Research Article

\title{
Influencing Factors of Disturbance Effects of Blasting and Driving of Deep Mine Roadway Groups
}

\author{
Jiaguang Kan, ${ }^{1}$ Peng Wang, ${ }^{2}$ and Peng Wang $\mathbb{D}^{1}$ \\ ${ }^{1}$ Key Laboratory of Deep Coal Resource Mining of the Ministry of Education, School of Mines, \\ China University of Mining and Technology, Xuzhou 221116, China \\ ${ }^{2}$ China University of Mining and Technology-Beijing, Beijing 100083, China \\ Correspondence should be addressed to Peng Wang; wangpeng19@cumt.edu.cn
}

Received 14 August 2020; Revised 14 September 2020; Accepted 13 February 2021; Published 3 March 2021

Academic Editor: Qing Ma

Copyright ( 2021 Jiaguang Kan et al. This is an open access article distributed under the Creative Commons Attribution License, which permits unrestricted use, distribution, and reproduction in any medium, provided the original work is properly cited.

The development and application of roadway group layout methods in coal mines have become more common and the mutual disturbance of blasting and driving of roadway groups has also become more prominent at depth. To improve the stability of rock mass surrounding roadways, we performed a systematic study on the factors that influence blasting and driving disturbances of adjacent roadways in deep mine roadway groups. We use the dynamic analysis module in FLAC3D to obtain the influence laws of three factors on the disturbance effects of adjacent roadways, namely, excavation methods, layer position changes of the roadway group, and whether or not bolt support is applied in the first roadway. Blasting strongly influences the surrounding roadway and increased horizontal distance can effectively reduce the disturbance effects of blasting and driving between adjacent roadways compared with increased vertical distance. Bolt support of the first excavated roadway enhances the roadway integrity and better stabilizes the rock structure surrounding the roadway. Industrial tests were carried out on three uphill roadways in the Gubei no. 1 mine (6-2). The monitoring results show that the movement of the roof and floor of the floor uphill return wind roadway is larger than that on the two sides. There is no notable change in the deformation speed of the surrounding rock in the floor return air roadway, but the deformation speed of the uphill conveyor belt roadway changes significantly. The results show that when the blasting excavation of a deep mine roadway group is more than five times the tunnel spacing, the increased horizontal distance effectively reduces the disturbance effects of excavation between adjacent roadways, which is consistent with the simulation results.

\section{Introduction}

The total length of newly excavated roadways in Chinese coal mines exceeds $1.4 \times 104 \mathrm{~km}$ annually. Blasting remains the most economical and practical way to break a rock in rock roadways $[1,2]$. With the expansion of mine design capacity, safe mine production has become increasingly difficult using a single roadway; two, three, or even multiple roadway development and deployment methods have therefore become a necessary choice $[3,4]$. The increase of mining depth further introduces roadway effects, such as high ground stress, high ground temperature, high permeability pressure, and mining disturbances, and the appearance of rock pressure is particularly complicated [5-7]. To ensure the stability of rock surrounding roadways and production safety, systematic research on the factors that influence the blasting and excavation disturbances of adjacent roadways in deep mine roadway groups has therefore become increasingly prominent.

Severe loads and shock waves are generated during blasting construction, which extends cracks in the surrounding rock, expands the loose circle, reduces the overall structure stability, and can even lead to collapse and/or damage accidents. Previous studies have extensively addressed the law of shock wave transmission and load on surrounding rock during construction blasting using laboratory tests to measure wave speeds and amplitude attenuation coefficients of different waveforms, combined with a 
dynamic damage calculation model to study the formation mechanism of the blasting seismic waves and decay law [8-10]. Field blasting test methods have also been used to study the vibration field distribution around tunnels or hydraulic engineering rock mass at close range and combined with particle vibration velocities to determine the seismic wave transmission distance and direction $[11,12]$. Vibration effects caused by blasting pose the primary impact on existing tunnels (roadways). The seismic wave and load generated by blasting damage in the surrounding rock is an energy dissipation process that exerts the greatest damage on the surrounding rock surface. Although the rock mass in the middle and far areas is insufficient to directly cause rock fracture, further damage can be inflicted on weak surfaces (e.g., joints, bedding, and fissures), thereby affecting the stability of the rock structure surrounding adjacent roadways [13-15]. Numerical simulation methods have been used to study the influence of the relative position of a double tunnel on stability, problems associated with construction procedures, and mutual disturbances during construction [16-18]. Several studies have also addressed the stability of the surrounding rock of double-lane tunnels during blasting and tunneling, including analysis of the impact of blasting construction on urban double-lane tunnels with small spacing based on field measurement data and the mechanical behavior characteristics of the rock wall during construction blasting of double-line small-distance tunnels [19, 20].

Reinforcement technical measures have been proposed to ensure rock wall stability. The vibration of an existing tunnel under different surrounding rock types and tunnel spacing conditions has been analyzed using ANSYS software to determine the influence of existing tunnels on the vibration of adjacent tunnels [21]. For coal mine roadways, a study has investigated the propagation law and influence of disturbance stress during driving and blasting and simulated the influence of single blasting distance on the disturbance effects of adjacent roadways. A higher number of blasting disturbances has been shown to lead to more serious deformation of the surrounding rock near the roadway. Increasing the one-time blasting excavation length is beneficial for reducing the disturbance effects of short-distance roadway excavation [22]. However, the mutual disturbance of roadway groups is mostly concentrated on the deformation and failure characteristics of the rock surrounding the roadway under the dynamic pressure during coal mining [23-25]. In summary, previous blasting disturbance studies mostly focused on tunnel construction (e.g., subways and bridges) and the influence of a blasting disturbance on adjacent roadways in coal mines is mostly considered to originate from the disturbance damage and failure mechanism of the excavated rock mass. However, comprehensive analysis of the factors that influence the disturbance effects of blasting and excavation in deep coal mine roadway groups remains scarce. Furthermore, the effects of dynamic disturbances from the driving method and changes of roadway space level remain poorly understood.

In this study, we used the FLAC3D dynamic load module to analyze the influence of two blasting and fully mechanized excavation methods, the spatial layer change of the roadway group, and the impact of bolt reinforcement on the adjacent roadways. The disturbance law of adjacent roadway excavation blasting is obtained based on the principal stress distribution and particle vibration. Industrial tests were carried out in three uphill roadways of the Gubei no. 1 mine (6-2), and the monitoring results verify the conclusions of the simulation analysis.

\section{Materials and Methods}

2.1. Engineering Background. The Gubei no. 1 mine is located in Fengtai County, Huainan City, Anhui Province, China, with an annual output of 6 million tons. The special return airway for the sixth coal floor of the Beiyi (6-2) uphill mining area is located in the northwest area of the $648 \mathrm{~m}$ deep pit bottom depot. The driving section is located between the 6-2 coal and 1 coal seam from the Beiyi (6-2) mining area. The gate of the return air stone gate was constructed with an azimuth angle of $303^{\circ}$ and the six coal floors with an average vertical distance of $20 \mathrm{~m}$. The roadways were arranged parallel to include three roadways of six uphill coal conveyor belts, six uphill coal floor return air tunnels, and six uphill coal floor tracks with horizontal distances of 30, 40, and $60 \mathrm{~m}$, respectively. The six uphill coal conveyor belts underwent roadway excavation in the 6-2 coal seam, and the remaining two roadways are at the same level as the special return air roadway for the sixth coal floor. The excavation layer of the no. 6 coal floor special return air tunnel is mainly located in interbedded mudstone and sandmudstone. The roof lithology is mainly fine sandstone, coal, and mudstone, and the floor is mainly interbedded sandmudstone and fine sandstone.

The horizontal distances between the floor dedicated return air tunnel and the uphill floor return air roadway and uphill conveyor belt roadway are 30 and $40 \mathrm{~m}$, respectively, and the vertical distances are 0 and $20 \mathrm{~m}$. The section of the special return air tunnel for the no. 6 coal floor is a straight wall semicircular arch with dimensions of $5.4 \times 4.3 \mathrm{~m}$ (width $\times$ height). The supporting form adopted at this stage is a single shed support. U29 steel is used for normal tunneling with a shed distance of $600 \mathrm{~mm}$, and U36 steel is used for the abnormal zone with a shed distance of $500 \mathrm{~mm}$. Each shed is constructed with four pairs of cable clamps with a $300 \mathrm{~mm}$ spacing and four tie bars. Blasting is presently adopted with daily footage of $6 \mathrm{~m}$ (10 sheds).

The section of the no. 6 uphill coal floor return air and uphill roadway conveyor belt is a straight wall semicircular arch with dimensions of $5.4 \times 3.8 \mathrm{~m}$. U29 metal sheds are used for support, the shed spacing is $600 \mathrm{~mm}$, each shed is constructed with four cable pairs, the cable spacing is $300 \mathrm{~mm}$, and there are four braces. A portion of the severely deformed section is supplemented with anchor cables or bolts on the roof and roadway shoulder angles, as shown in Figure 1.

2.2. Rock Failure Mechanism of Roadway Blasting. To study the impact of blasting and excavation disturbance in deepwell tunnels, it is necessary to study the propagation of 


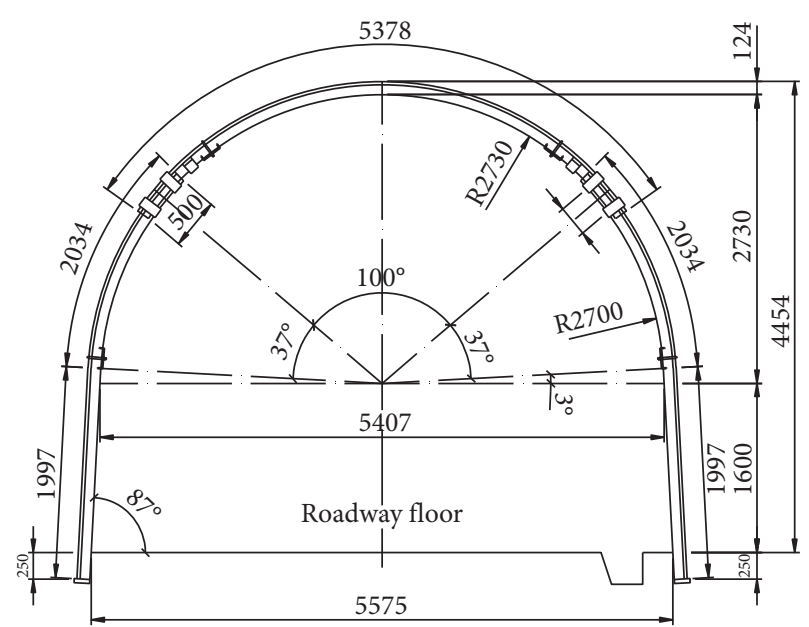

FIGURE 1: Schematic diagram of supporting in the no. 6 uphill coal floor return air.

vibrational waves during blasting, especially how blasting relates to the damage mechanism in rocks [26]. Livingston rock blasting funnel theory asserts that the amount of energy transferred to the rock when a charge explodes depends on several factors, including the nature of the rock medium, the explosive performance, and the amount and depth of the charge.

Roadway excavation blasting is a part of semi-infinite rock blasting, or blasting in free-surface rock mass. A rock drill is used during tunneling to bore cylindrical holes on the tunneling face, embed the charge in the rock, and form a tight seal. When the charge explodes, aside from the formation of crushing and fissure areas in the rock behind the charge, the rock near the free surface is broken and thrown out to form a funnel-shaped pit or a blasting funnel outside the vibration zone, as shown in Figure 2.

When there is a free surface in the rock mass, blasting causes a shock wave to propagate around the blasting source inside the rock mass. Before the shock wave reaches the free surface, the high-pressure rock mass points move radially while the outer solid rock inevitably restricts this movement [27]. When the blasting shock wave reaches the rock free surface, the radial movement of the particles is no longer restricted by the outer rock and the rock mass moves freely outside. Under intense movement, rocks near the free surface are thrown out to form an external destruction zone for blasting. The free surface of a rock mass is the interface between the air and rock mass, across which incident waves are reflected. When the incident compression wave propagates to the free surface, it produces a reflected wave or tensile stress wave that propagates in the explosion source direction within the rock mass. The stress and strain state of the rock can be very complicated under the combined action of the incident compression wave and reflected tensile stress wave. The rock near the free surface initially produces radial cracks. Rocks in the external damage zone are then thrown out from the free surface under the action of the blasting gas to form a blasting funnel. Rock damage near the free surface is caused by the superposition of incident waves and

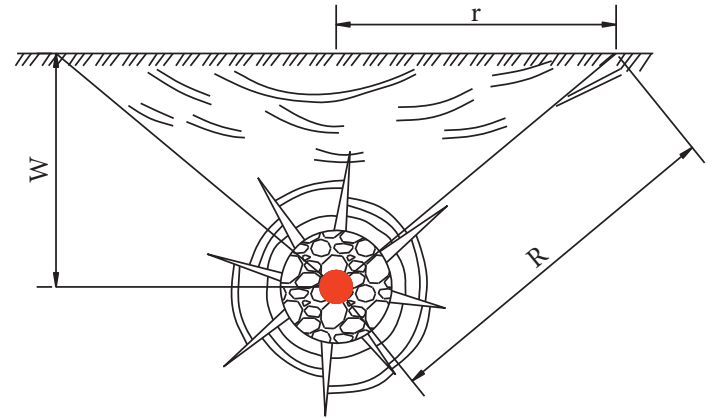

FIgURE 2: Blasting crater formation schematic diagram. W: minimum resist line; R: broken radius; r: blasting crater radius.

reflected waves. A portion of the energy generated by explosive blasting is consumed in the crushing and fissure zones, another portion is converted into the kinetic energy of the blasting funnel and broken rock mass, and another portion is converted into sound and explosive shock waves. The remaining energy propagates outward in the form of explosive shock waves.

2.3. Numerical Simulation Model. Deep mine roadway groups are complex projects with several factors that affect the blasting disturbance effects. We mainly investigate the influence of three types of external factors on the stability of rock surrounding a blasting roadway group: driving methods, spatial layer changes, and whether or not the first roadway is bolted. FLAC3D is used in the calculations to establish a threedimensional numerical model. The model adopts the Mohr-Coulomb yield criterion with dimensions of $100 \times 10 \times 60 \mathrm{~m}(x \times y \times z)$. The roadway forms a straight wall semicircular arch with dimensions of $6 \times 5 \mathrm{~m}$ (width $\times$ height) and the roadway location is determined according to the different influencing factors. The mesh size of the dynamic analysis model is controlled by the shortest wavelength of the input wave. Suppose the maximum size of the grid is $\Delta \mathrm{l}$ and the shortest wavelength of the input wave is $\lambda$. To express wave propagation, the model should satisfy $\Delta \mathrm{l}<(1 / 10-1 / 8) \lambda$. Combined with the applied stress wave, the maximum mesh size is $1 \mathrm{~m}$; thus the model chooses the maximum mesh size as $1 \mathrm{~m}$. The dynamic analysis also requires relatively uniform grid divisions, and the ratio of the largest to smallest grid size cannot exceed 5.

The model adopts the Mohr-Coulomb yield criterion, imposes a static boundary on the left and right and front and back, all lower boundaries are set as fixed displacement constraints, and the upper boundary is the stress boundary. According to the overlying strata thickness, a uniform load of $20 \mathrm{MPa}$ is applied to the top surface (burial depth $=800 \mathrm{~m}$, average density of the overlying strata $=2500 \mathrm{~kg} / \mathrm{m} 3$ ). The model range is regarded as homogeneous single rock material to reduce the calculation workload, and the rock mechanical parameters are selected according to laboratory experiments (Table 1).

Static excavation is used in the calculation to simulate comprehensive excavation construction. A dynamic load is applied on the basis of static excavation to simulate drilling 
TABLe 1: Physical and mechanical parameters of rock.

\begin{tabular}{llllll}
\hline Density $\left(\mathrm{kg} \times \mathrm{m}^{3}\right)$ & Cohesion (MPa) & Internal friction angle $\left({ }^{\circ}\right)$ & Shear modulus (GPa) & Bulk modulus (GPa) & Tensile strength (MPa) \\
\hline
\end{tabular}

and blasting construction. In this simulation, a section of blasting seismic wave recorded by actual monitoring is used as input dynamic load. Its duration is more than 4000 steps, the period is about $0.02 \mathrm{~s}$, the dynamic application time is $0.1 \mathrm{~s}$, and the overall simulation time is $0.3 \mathrm{~s}$. And the three influencing factors are combined to establish numerical models, as shown in Figure 3.

\section{Results and Analysis}

3.1. Influence of Different Tunneling Methods on Disturbance Effects. The energy attenuation of the blasting seismic wave is closely related to the particle vibration velocity with regard to the blasting vibration safety criterion. Most countries use particle vibration velocity as an indicator to measure blasting vibration intensity. The displacement of particles and vibration velocities are therefore monitored in the rock surrounding the first excavated roadway in the $\mathrm{x}$ - and $\mathrm{z}$-directions. Measured points are set on the vault of the two sides, arch toe, and floor of the roadway. The layout of the measurement points is shown in Figure 4.

The horizontal principal stress of the first excavated roadway is monitored in the two cases of comprehensive excavation and blast excavation, as shown in Figure 5.

The pressure on the roof and floor plate of the first excavated roadway significantly increases during blast excavation compared with fully mechanized excavation. This is because the vertical and horizontal reverse tensile stresses on the rock increase under the action of horizontal blasting stress waves and shock waves, which cause the roof and floor stress to increase, resulting in radial and circumferential cracks.

The displacement of mass points 2 and 8 was monitored in the $x$-direction and mass points 5 and 10 in the $z$-direction. The displacement changes of each mass point are shown in Figure 6.

When using static excavation (i.e., with a fully mechanized excavation machine), the displacement changes of each mass point of the first excavation roadway are $8.8 \mathrm{~mm}$ of vault sinking, $10 \mathrm{~mm}$ of floor rise, $7.2 \mathrm{~mm}$ of left side displacement, and $7.4 \mathrm{~mm}$ of right side displacement. The displacement change of the roof and floor is greater than that of the side siding, whereas the explosion-facing side siding displacement is not significantly greater than that of the left siding. Compared with comprehensive excavation, the displacement of each particle does not significantly increase in blast tunneling mode, whereas the vibration time of each particle is significantly longer. This is because the distance between the roadways is $30 \mathrm{~m}$ and the roadways are in the middle and far zones of the blasting vibration. The blasting seismic wave propagates in the rock mass, largely causing particle vibration, and cracks essentially no longer form, thus the displacement change is small. The time required for final stability is longer owing to the particle vibration.
The seismic wave during blasting and tunneling causes strong vibrations of the internal rock mass particles, which have a nonnegligible impact on the surrounding rock of the adjacent roadway. The vibration speed of the surrounding rock during tunneling of the fully mechanized excavator can be ignored. The results show that under lateral blasting load conditions, the horizontal vibration speed of each part of the adjacent roadway is substantially higher than the vertical vibration speed. This section mainly focuses on the peak vibration velocity analysis of particles in the $x$-direction as the failure criterion.

Figure 7 shows that the vibration velocity of each particle generally assumes a harmonic form over time. The peak vibration velocity of each monitoring point is analyzed to determine the law of the first excavation roadway disturbed by blasting and excavation of the adjacent roadway. The peak vibration velocity of each monitoring point is taken as the object for analysis. Table 2 counts the peak vibration velocities in the $X$ direction of each monitoring point and displays the results in the form of Figure 8 .

When the adjacent roadway is driven by blasting, the peak vibration velocity of the straight wall area on the explosion side of the first excavation roadway is the largest, reaching $2.84 \mathrm{~mm} / \mathrm{s}$. The vibration velocity of the upper arch area of the straight wall on the front explosion side is second only to the middle of the straight wall, reaching $2.52 \mathrm{~mm} / \mathrm{s}$, while the vibration velocity of the upper part of the straight wall on the back explosion side is the smallest $(0.814 \mathrm{~mm} / \mathrm{s})$. Different parts of the roadway respond differently to the effects of blasting vibration, and the maximum peak vibration velocity appears in the area of the straight wall and arch on the explosion side of the roadway. This is the area most affected by blasting and excavation and most prone to damage. Attention should therefore be paid to support strengthening. The vibration speed at the dome is less than that of the front explosion side but higher than that of the floor plate and back explosion side and may also be damaged by vibration owing to the influence of its own gravity. The vibration speed of the back explosion side is relatively small: only about $1 / 4$ that of the front explosion side, which is minimally affected by blasting/tunneling and is relatively safe.

3.2. Disturbance Effects of Spatial Position Change of the Roadway Group. Figures 9 and 10 show the monitoring results of the horizontal principal stress of the model during excavation on the left and right and the loading of seismic waves.

The loading seismic waves disturb the first excavated roadway. The maximum principal stress changes on the left and right sides of the first excavated roadway are monitored during the entire simulation process, as shown in Figures 11 and 12 . 


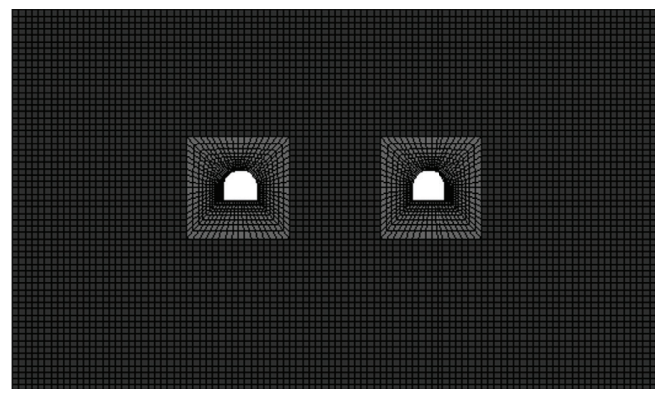

(a)
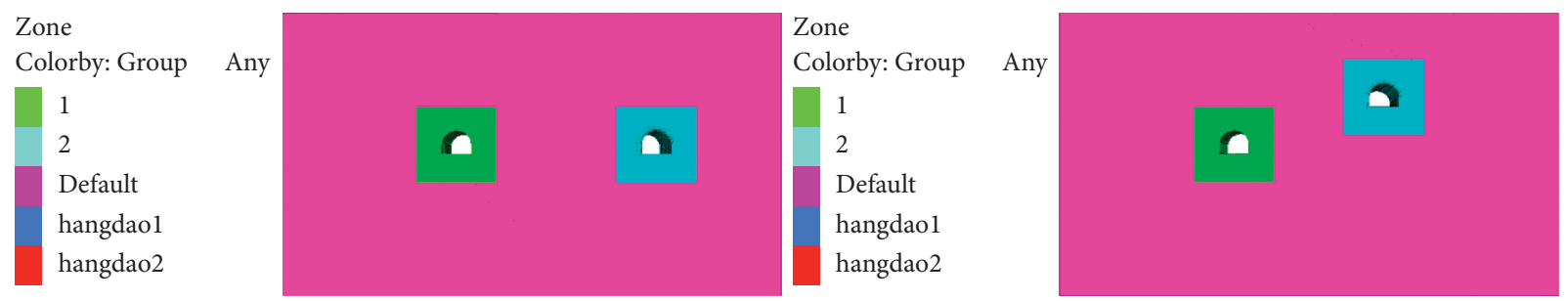

(b)
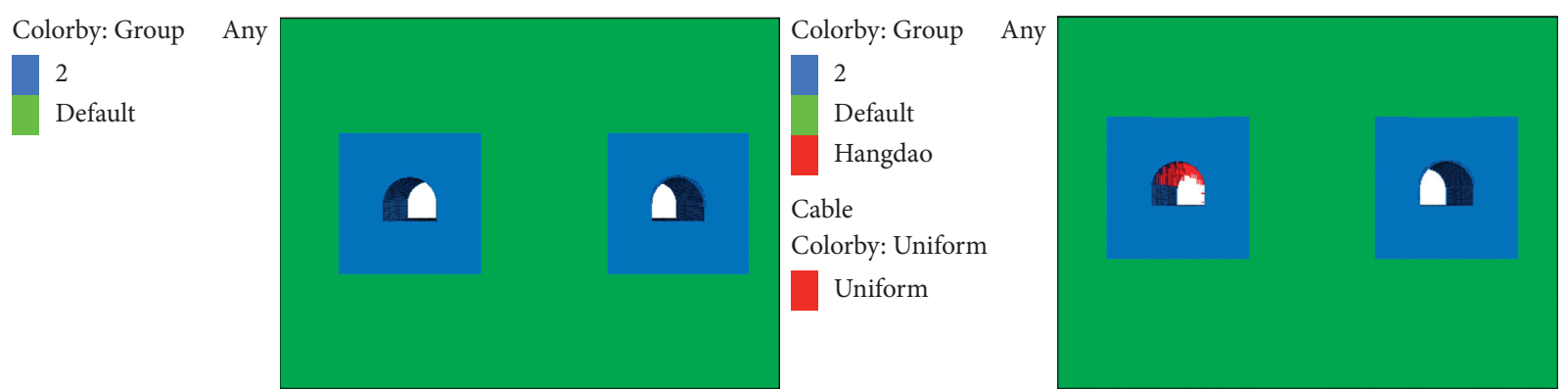

(c)

Figure 3: Numerical analysis model: (a) model with $30 \mathrm{~m}$ spacing between roadways at the same level; (b) model of 10-horizontal movement and 10-vertical movement; and (c) model with the bolt anchorage of ahead roadway or not.

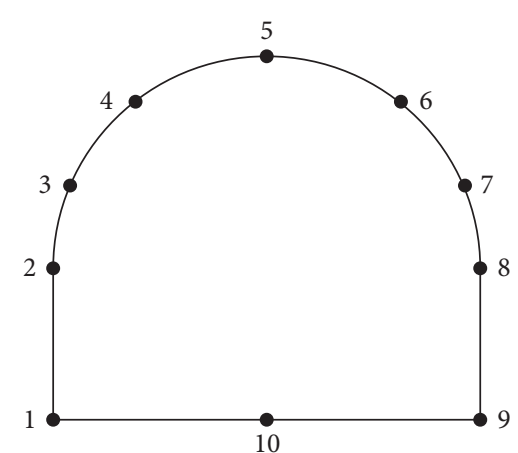

Figure 4: Monitoring stations plan.

The average maximum principal stress of the left and right sides of the roadway excavated by the $10 \mathrm{~m}$ horizontal movement model is $1.596 \mathrm{e} 5$ and $1.565 \mathrm{e} 5$, respectively. The average maximum principal stress of the left and right sides of the roadway with a vertical movement of $10 \mathrm{~m}$ is $1.940 \mathrm{e} 5$ and $1.715 \mathrm{e} 5$, respectively. In the model with $10 \mathrm{~m}$ of vertical movement, the maximum principal stress also strongly fluctuates because the right side is close to the back driving roadway.
The $10 \mathrm{~m}$ horizontal movement model can therefore more significantly reduce the stress on the adjacent roadway compared with the $10 \mathrm{~m}$ vertical movement model.

Figures 13 and 14 show the vibration velocity curves of the rock surrounding the roadway under the two layout modes. Under the horizontal movement model, the vibration intensity of each monitoring point is notably stronger than that of the vertical movement model. The maximum vibration velocity of the surrounding rock when moving horizontally is $1.08 \times 10^{-3} \mathrm{~m} / \mathrm{s}$ on the roof, $0.97 \times 10^{-3} \mathrm{~m} / \mathrm{s}$ on the floor, $0.75 \times 10^{-3} \mathrm{~m} / \mathrm{s}$ on the left side, and $1.28 \times 10^{-3} \mathrm{~m} / \mathrm{s}$ on the right side. The maximum vibration velocity of the surrounding rock when moving vertically is $2.4 \times 10^{-3} \mathrm{~m} / \mathrm{s}$ on the roof, $1.24 \times 10^{-3} \mathrm{~m} / \mathrm{s}$ on the floor, $0.75 \times 10^{-3} \mathrm{~m} / \mathrm{s}$ on the left side, and $2.68 \times 10^{-3} \mathrm{~m} /$ $\mathrm{s}$ on the right side. When moving vertically, the initial peak vibration speeds of the roof, right side, and floor of the roadway excavated are notably higher than when moving horizontally. In summary, increased horizontal distance can effectively reduce the disturbance effects of blasting and excavation between adjacent roadways compared with a change of vertical distance. 
Contour of XX-stress

Calculated by: volumertic/ averaging

$-1.3344 E+05$ $-2.5000 E+06$

$-5.0000 E+06$

$-7.5000 E+06$

$-1.0000 E+07$

$-1.2500 E+07$

$-1.5000 E+07$

-1.7500E+07

(1.7500E+ 07

-

$-2.2500 E+07$

$-2.5000 E+07$

$-2.7500 E+07$

$-3.0000 E+07$

$-3.2500 E+07$

-

$-3.7500 E+07$

$-3.7618 E+07$

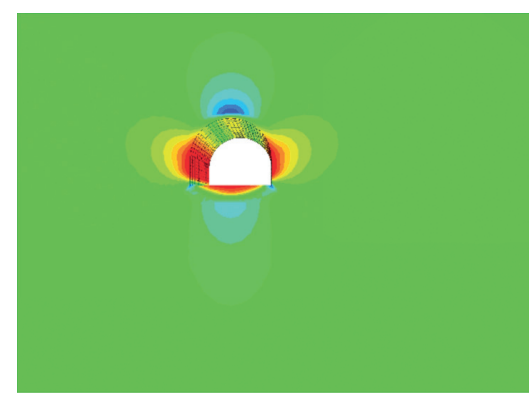

(a)
Contour of XX-stress

Calculated by: volumertic/ averaging

$2.0476 E+05$ $0.0000 E+00$

$-2.5000 E+06$

$-5.0000 E+06$

$-7.5000 E+06$

$-1.0000 E+07$

$-1.2500 E+07$

$-1.5000 E+07$

1.7500E + 07

(.7500E + 07

- $2.0000 E+07$

$-2.2500 \mathrm{E}+07$

$-2.5000 E+07$

$-2.7500 E+07$

$-3.0000 E+07$

$-3.2500 E+07$

$-3.5000 E+07$

$-3.6892 E+07$

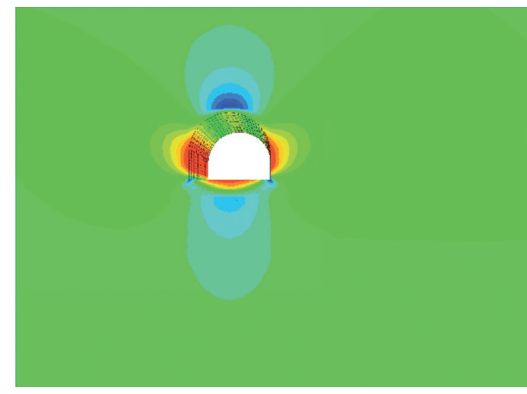

(b)

FIgURE 5: Horizontal stress of ahead roadway: (a) fully mechanized excavation and (b) blast excavation.

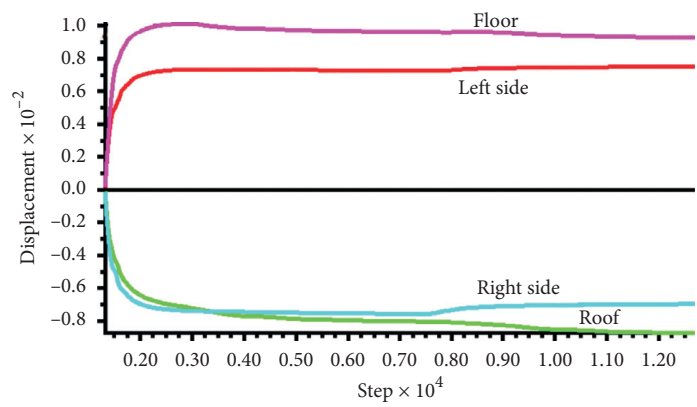

(a)

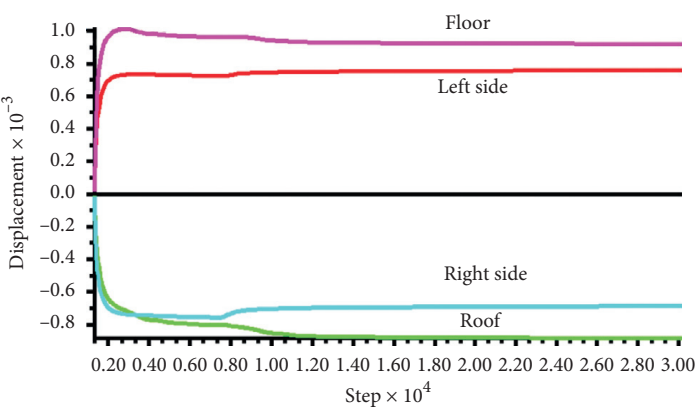

(b)

FIGURE 6: Displacement of ahead roadway versus time of right side: (a) fully mechanized excavation and (b) blast excavation.

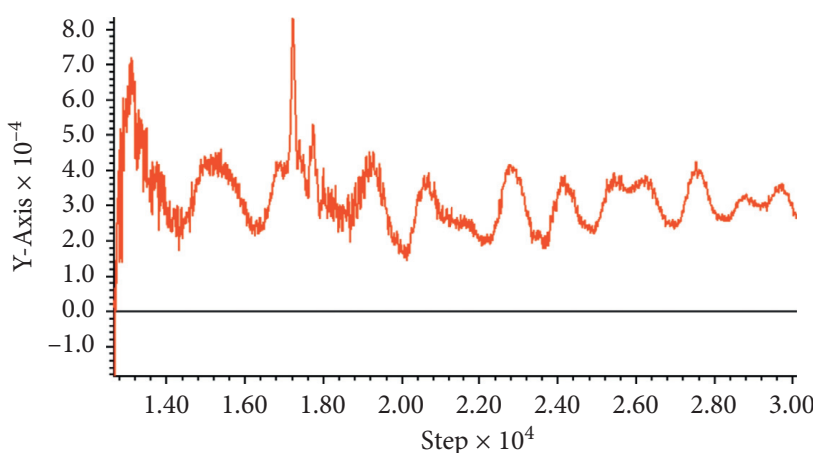

(a)

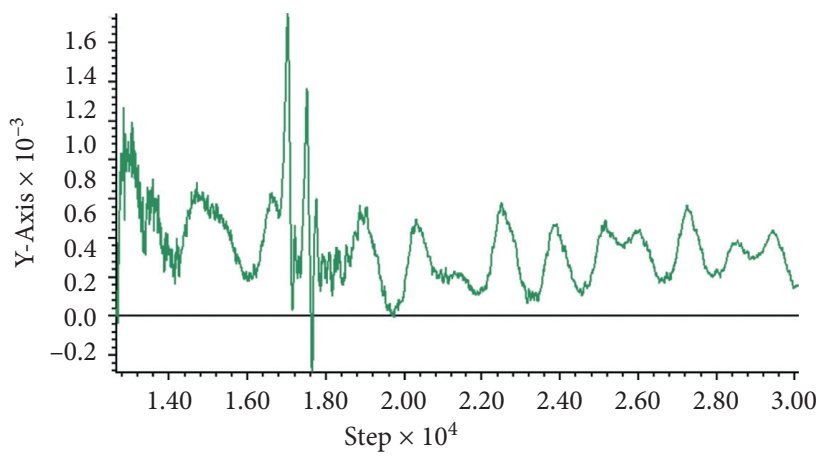

(c)

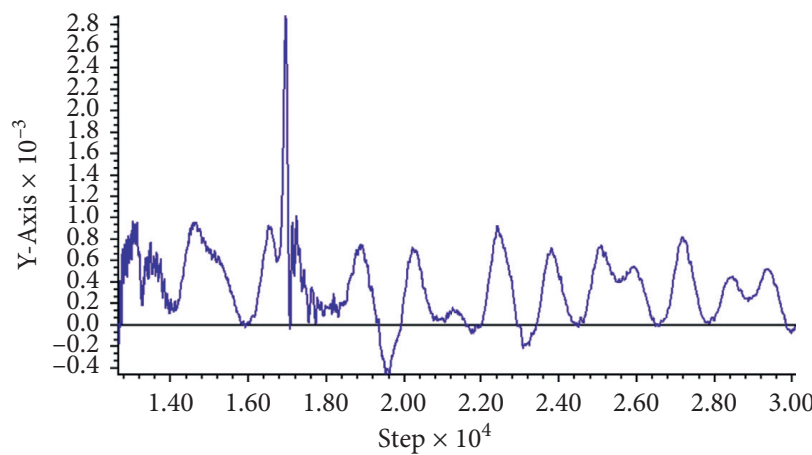

(b)

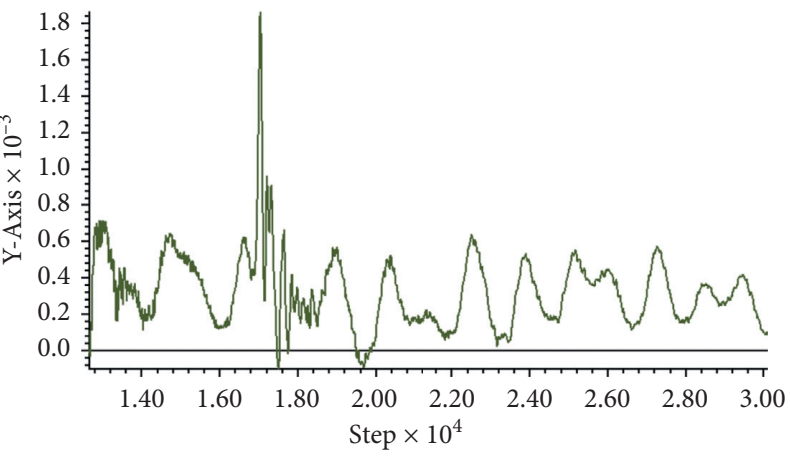

(d)

FIGURE 7: Vibration velocity of all particles: (a) left side, (b) right side, (c) roof, and (d) floor. 
TABLE 2: The peak vibration velocity of $X$ direction of each point in roadway.

\begin{tabular}{lcccccccccc}
\hline Monitoring point number & 1 & 2 & 3 & 4 & 5 & 6 & 7 & 8 & 9 & 10 \\
\hline Peak vibration speed $\left(10^{-3} \mathrm{~m} / \mathrm{s}\right)$ & 1.22 & 0.84 & 0.81 & 1.14 & 1.54 & 2.26 & 2.52 & 2.84 & 2.46 & 1.44 \\
\hline
\end{tabular}

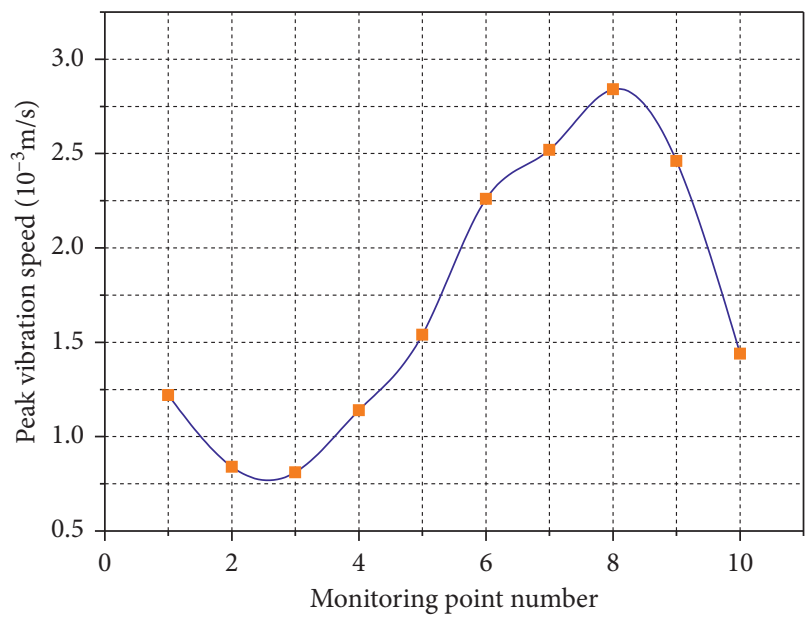

FIgURE 8: Distribution curve of the biggest vibration velocity of $X$ direction of each point in roadway.

\subsection{Disturbance Effects of Bolt Reinforcement in the First} Excavation Roadway. We monitored the displacement of the roof, left, right, and floor of the first excavated roadway, and the results are shown in Figures 15 and 16.

Without bolt support, the total displacement changes of the roof, left, and right sides of the first excavated roadway are $8.868,7.612$, and $6.861 \mathrm{~mm}$, respectively; with bolt support, the total displacement changes are $8.746,7.586$, and $6.828 \mathrm{~mm}$. The total displacement change is smaller when the first excavation roadway has bolt support. Without bolt support, the total displacement of the roadway floor is $9.188 \mathrm{~mm}$; in the case of bolt support, the displacement change of the floor plate is $9.527 \mathrm{~mm}$. The floor is not reinforced when the roadway is supported, which results in increased floor displacement.

Figures 17 and 18 show the vibration velocity curves of the rock surrounding the roadway with and without support. The peak vibration velocities of each particle under no support conditions are $1.54 \times 10^{-3} \mathrm{~m} / \mathrm{s}$ on the roof, $0.84 \times 10^{-3} \mathrm{~m} / \mathrm{s}$ on the left side, and $2.84 \times 10^{-3} \mathrm{~m} / \mathrm{s}$ on the right side. The peak vibration velocities of each particle under bolt support conditions are $1.62 \times 10^{-3} \mathrm{~m} / \mathrm{s}$ on the roof, $0.87 \times 10^{-3} \mathrm{~m} / \mathrm{s}$ on the left side, and $2.98 \times 10^{-3} \mathrm{~m} / \mathrm{s}$ on the right side. The particle vibration speed increases in the bolt support case compared with the no bolt support case. This is because bolt reinforcement strengthens the roadway integrity and makes the internal connection closer. Bolt support can enhance the roadway integrity, increasingly stabilize the surrounding rock structure, and effectively reduce the deformation of the surrounding rock. Reasonable support for the first excavated roadway can therefore reduce the impact of blasting excavation on the adjacent roadway disturbance.

\section{Industrial Tests}

4.1. Monitoring Station Layout. The monitoring content mainly includes the surface displacement and displacement speed of the roadway. The cross section method is used to collect measurements. Twenty-three measurement stations were arranged according to an actual roadway excavation situation, including 13 permanent measuring stations and 10 temporary simple measuring stations. Eight permanent monitoring stations were arranged in the uphill direction of the special return air passage for the no. 6 coal floor (B1-B8), 10 temporary simple measuring stations were arranged on the no. 6 uphill coal conveyor belt $\left(\mathrm{B}^{\prime}-\mathrm{B} 10^{\prime}\right)$, and 5 permanent measuring stations were arranged on the no. 6 uphill coal floor return air, as shown in Figure 19. The mine pressure observation instruments mainly include the special short bolt with hook nut, multipoint displacement meter, and anchor cable dynamometer.

\subsection{Monitoring Results and Discussion}

4.2.1. Impact of Blasting in the Special Return Airway on the Uphill Floor Return Air. The multisection method was used to analyze the convergence data of the uphill floor return air surface. The deformation curve and deformation speed curve of the two sides, roof, and floor were obtained within 1 month of the roadway excavation, as shown in Figure 20. In the initial observations, the special return air roadway for the floor lags head-on and the horizontal distance of the floor return air uphill station is $27 \mathrm{~m}$; at the end of the observations, the distance is $42 \mathrm{~m}$.

Figure 20 shows that the displacement of the two sides of the uphill return wind is $17 \mathrm{~mm}: 9 \mathrm{~mm}$ on the right side, $8 \mathrm{~mm}$ on the left side; the roof and floor plates move $46 \mathrm{~mm}$, the roof sink moves $12 \mathrm{~mm}$, and the floor drum moves $34 \mathrm{~mm}$. The roof and floor plates move closer than the two sides, and the floor drum sinks more severely than the roof plate, which is nearly 2.8 times that of the roof plate sinking amount and accounts for about $74 \%$ of the roof and floor plate movement. This is consistent with the displacement of the roof and floor of the adjacent roadways monitored in the simulations, which is greater than the two sides. The special return airway for the floor is within $30-50 \mathrm{~m}$ head-on from the uphill return air roadway of the floor. Upon excavation of the dedicated return air roadway, the two uphill floor return air roadway sides and the approaching speeds of the roof and floor all oscillate within a certain range. The movement speed of the two sides and roof sinking are essentially stable within the range of $0-5 \mathrm{~mm} / \mathrm{d}$, and those of the roof and floor are stable within the range of $2-4 \mathrm{~mm} / \mathrm{d}$. The heading position of the dedicated return airway differs and the deformation speed curve of the uphill floor return air roadway shows no apparent change. The blasting of the 


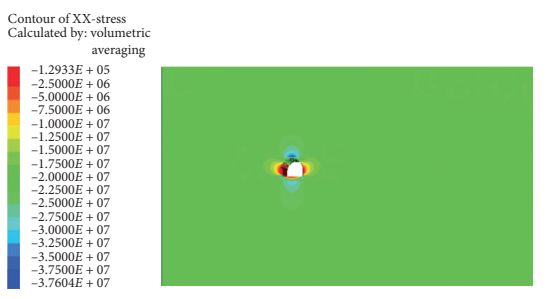

(a)
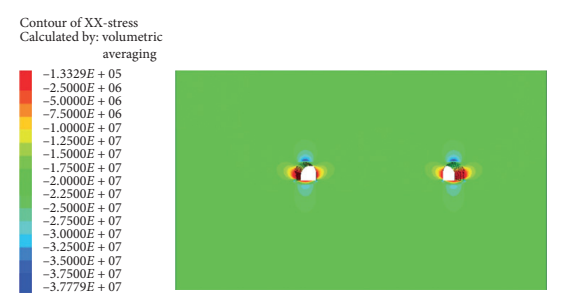

(b)

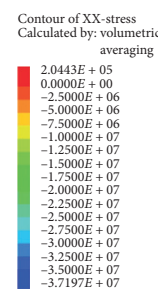

(1) (⿻)

(c)

FIGURE 9: Model principal stress distribution when the roadway moves horizontally for $10 \mathrm{~m}$ : (a) excavation of the left side roadway, (b) excavation of the right-side roadway, and (c) load seismic wave.

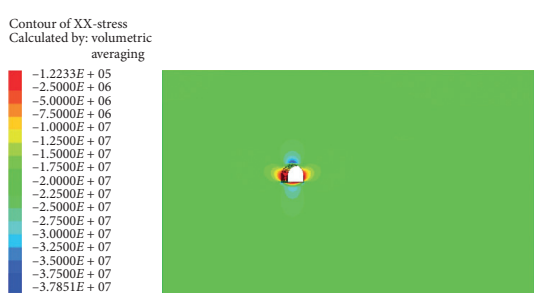

(a)
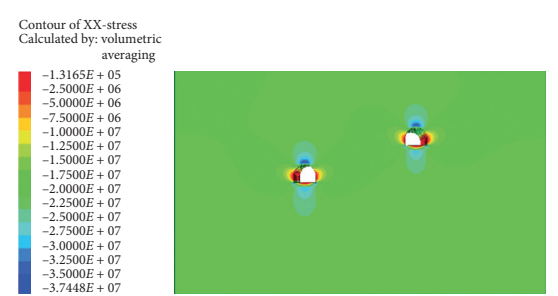

(b)
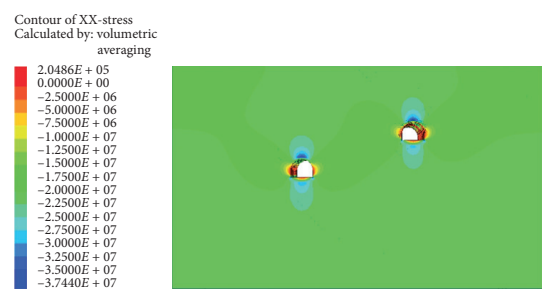

(c)

Figure 10: Model principal stress distribution when the roadway moves vertically for $10 \mathrm{~m}$ : (a) excavation of the left side roadway, (b) excavation of the right-side roadway, and (c) load seismic wave.

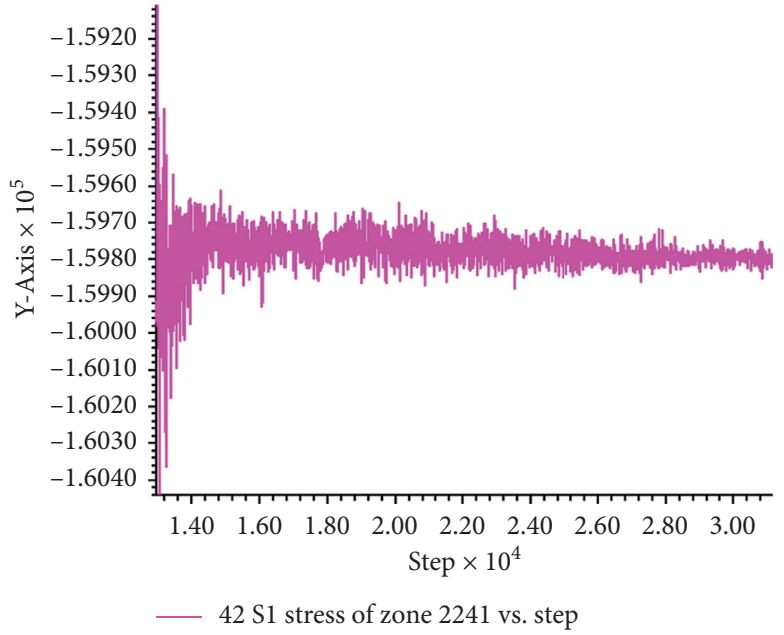

(a)

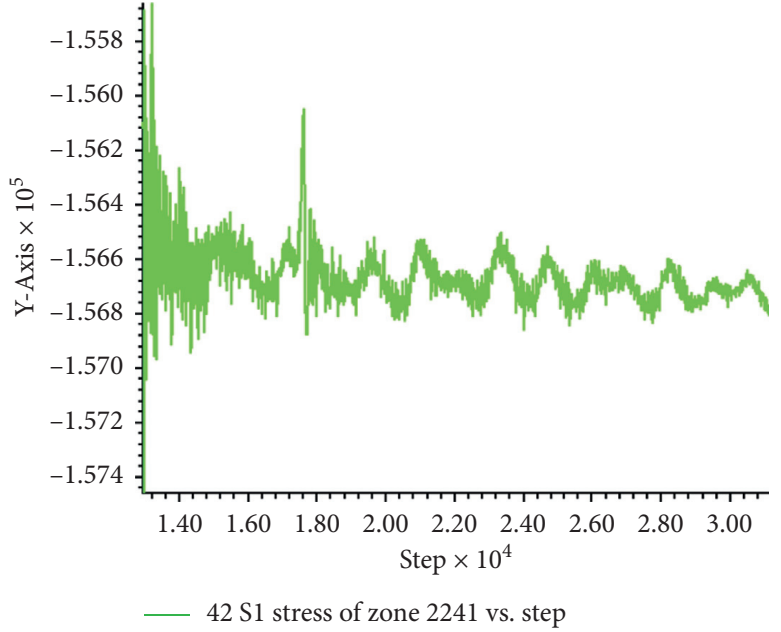

(b)

FIgURE 11: The maximum principal stress changes when the roadway moves horizontally for $10 \mathrm{~m}$ : (a) left side and (b) right side.

dedicated return airway does not affect the uphill floor return air roadway deformation.

\subsubsection{Impact of Blasting in Special Return Air Roadway on} the Uphill Roadway Conveyor Belt. The multisection method was used to analyze the surface convergence data of the uphill roadway by the conveyor belt and the deformation curve and deformation speed curve of the two sides and roof and floor were obtained within 1 month after blasting and driving of the roadway, as shown in Figure 21. In the initial observations, the horizontal distance of the special return air tunnel on the floor that lags behind the uphill conveyor belt roadway station is $60 \mathrm{~m}$; at the end of the observations, the horizontal distance of the leading uphill conveyor belt roadway station is $134 \mathrm{~m}$.

Figure 21 shows that the displacement of the two sides of the uphill roadway of the conveyor belt is $68 \mathrm{~mm}$. The moving distance of the roof and floor plates is $97 \mathrm{~mm}$, which is larger than that of the two sides. The floor drum moves $87 \mathrm{~mm}$, and the roof plate sink moves $10 \mathrm{~mm}$. Deformation of the roof plate is not substantial, and the floor drum 


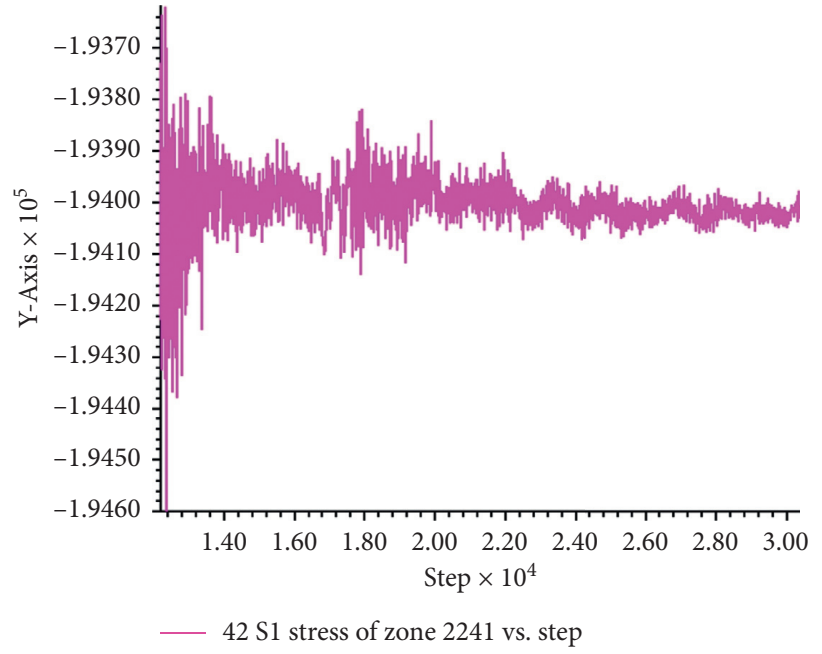

(a)

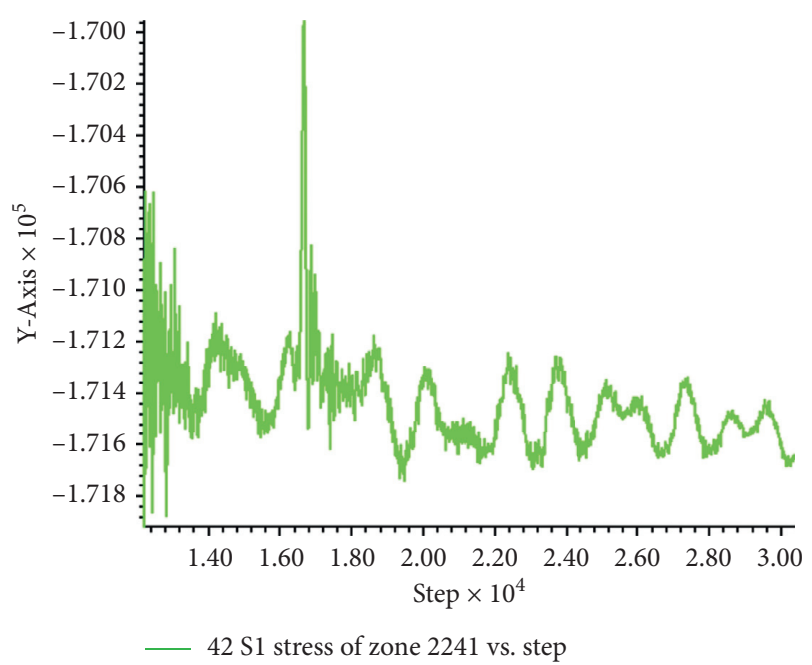

(b)

FIGURE 12: The maximum principal stress changes when the roadway moves vertically for $10 \mathrm{~m}$ : (a) left side and (b) right side.

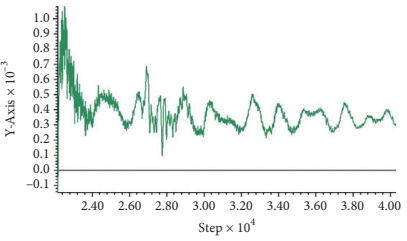

(a)

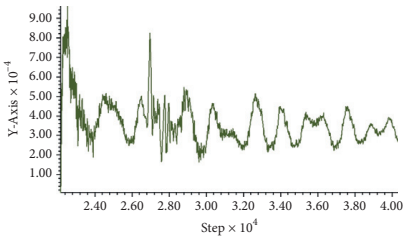

(b)

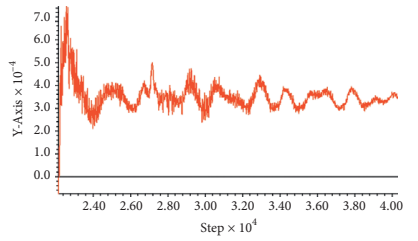

(c)

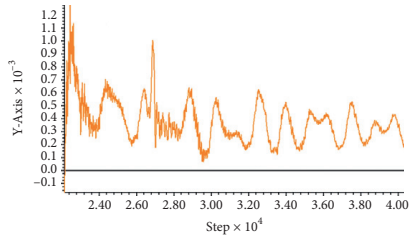

(d)

Figure 13: The vibration speed changes when the roadway moves horizontally for $10 \mathrm{~m}$ : (a) roof, (b) floor, (c) left side, and (d) right side.

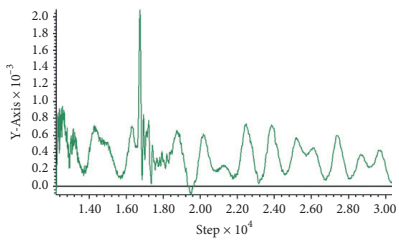

(a)

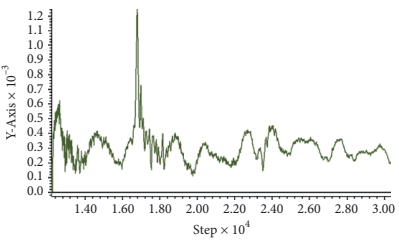

(b)

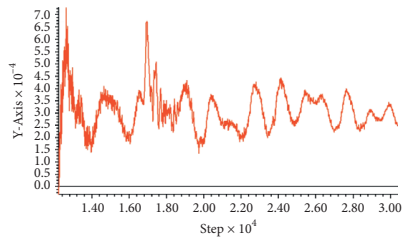

(c)

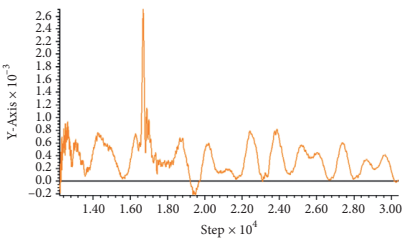

(d)

Figure 14: The vibration speed changes when the roadway moves vertically for 10 : (a) roof, (b) floor, (c) left side, and (d) right side.

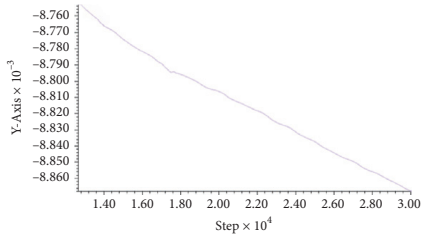

(a)

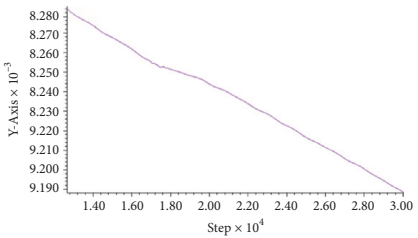

(b)

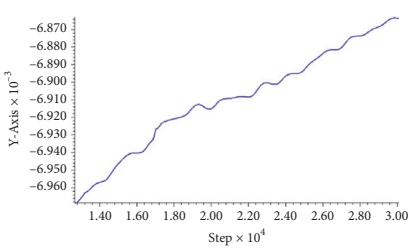

(d)

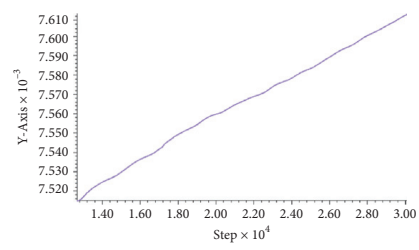

(c)

Figure 15: Deformation of surrounding rock when first excavated roadway without support: (a) roof, (b) floor, (c) left side, and (d) right side. 


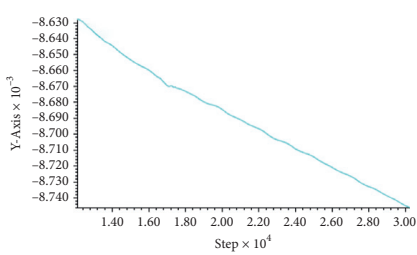

(a)

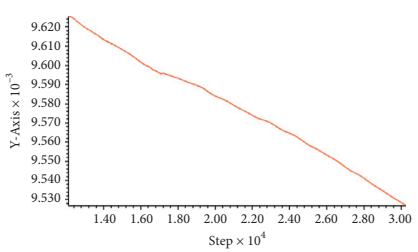

(b)

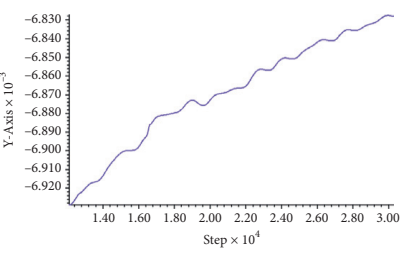

(d)

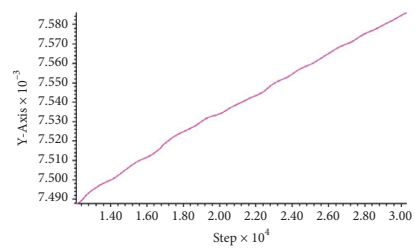

(c)

Figure 16: Deformation of surrounding rock when first excavated roadway with bolt support: (a) roof, (b) floor, (c) left side, and (d) right side.

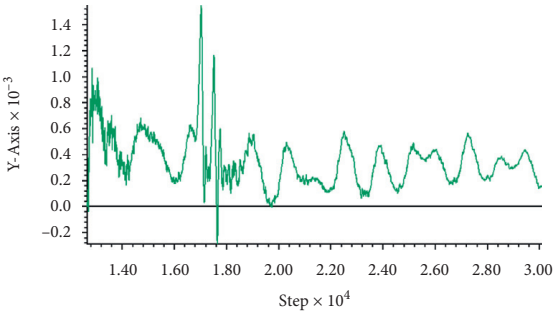

(a)

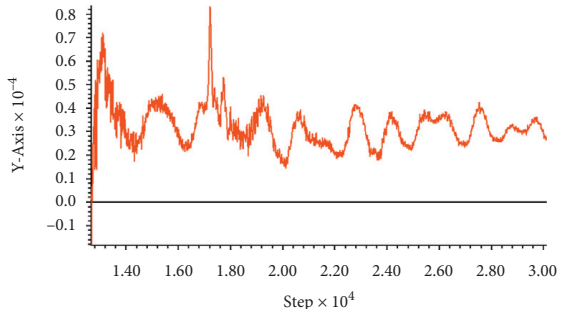

(b)

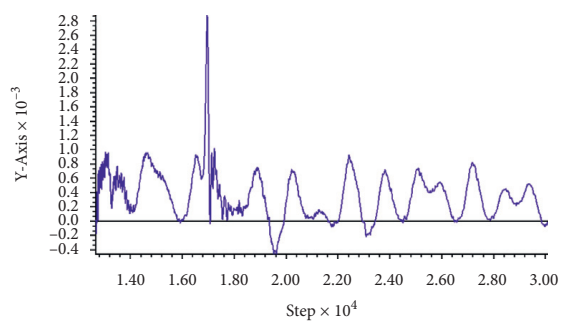

(c)

Figure 17: The vibration speed changes when first excavated roadway without support: (a) roof, (b) left side, and (c) right side.

volume is 8.7 times that of the sinking amount of the roof plate. Upon excavation of the special return air tunnel, the deformation speed curves of the two sides of the uphill tunnel and the roof and floor of the conveyor belt are roughly the same and show similar laws. When the special return air roadway lags behind the uphill conveyor belt roadway station, the fluctuation of the deformation speed of the two sides, roof, and floor increases and the amplitude decreases. The speed and fluctuations increase when the head-on position passes the station. The deformation speed reaches a maximum when the special return air tunnel is $30-50 \mathrm{~m}$ ahead of the uphill conveyor belt roadway station. With increasing lead distance of the dedicated return air tunnel, the deformation speed shows an oscillating downward trend and gradually stabilizes. The peak deformation speed of the two sides of the uphill belt transportation roadway is $5.6 \mathrm{~mm} / \mathrm{d}$. When lagging behind the special return airway by $120 \mathrm{~m}$, the deformation speed can be stabilized below $2 \mathrm{~mm} / \mathrm{d}$. The deformation speed of the roof plate is stabilized below $1 \mathrm{~mm} / \mathrm{d}$ and the peak deformation speed of the roof and floor plates is $6-7 \mathrm{~mm} / \mathrm{d}$. In addition, the impact of the head-on excavation slows with increasing head-on distance of the lagging dedicated return airway. At the end of the observations, the deformation speed value is below $2 \mathrm{~mm} / \mathrm{d}$.

According to the on-site measurements, the deformation of the roof and floor of the uphill floor return air roadway is larger than that of the two sides. There is no significant 


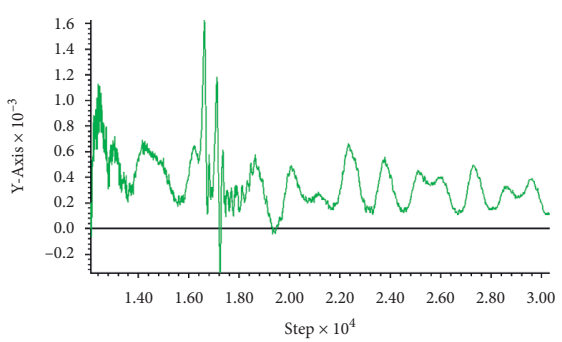

(a)

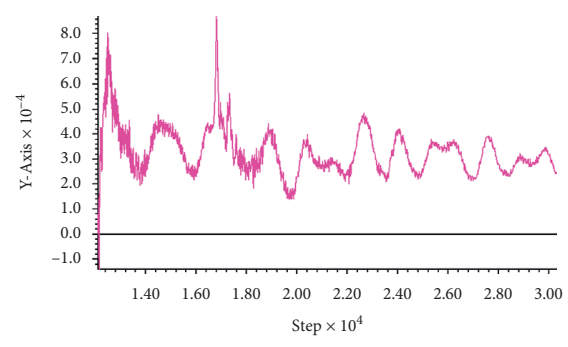

(b)

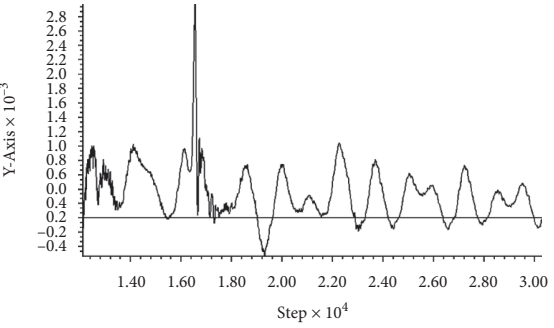

(c)

FIgURE 18: The vibration speed changes when first excavated roadway with bolt support: (a) roof, (b) left side, and (c) right side.

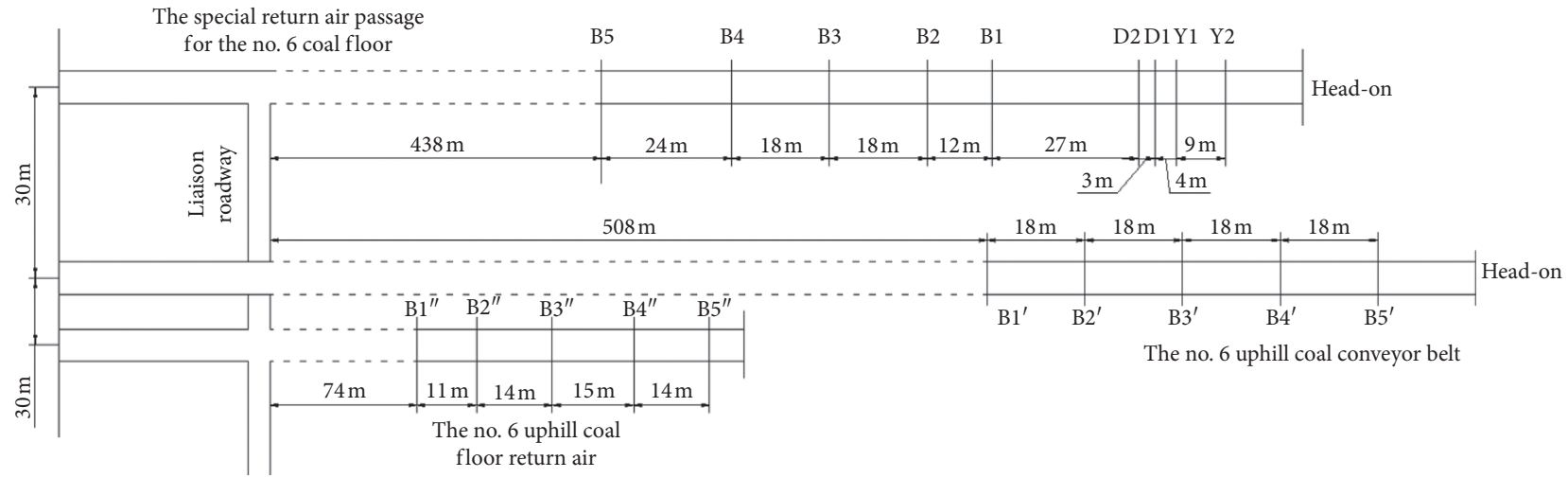

FIGURE 19: Schematic diagram of observation station arrangement.

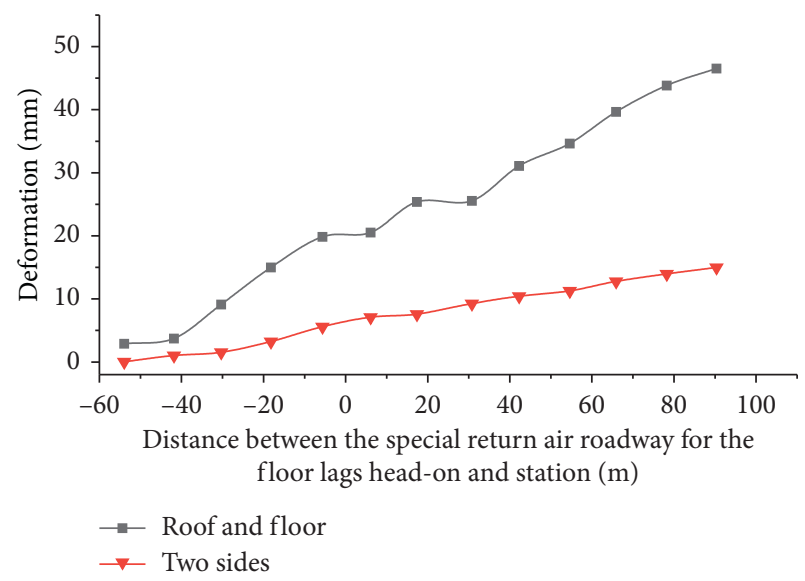

(a)

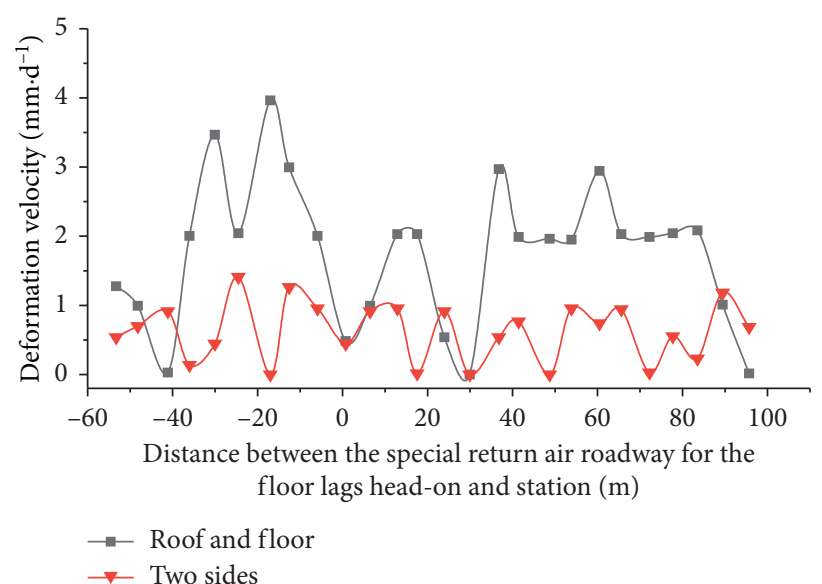

(b)

Figure 20: Deformation and deformation velocity of the floor return air uphill under the influence of special air-return roadway blast excavating: (a) deformation and (b) deformation velocity.

change in the surrounding rock deformation speed when the special floor return air roadway heads through the uphill floor return air roadway station, and the deformation speed curve of the uphill conveyor belt changes significantly. A comparison between the two shows that when blasting excavation of a deep mine roadway group is more than five times the length of the tunnel spacing, compared with the vertical distance, the increase of horizontal distance can effectively reduce the disturbance effects of the adjacent roadways. This verifies the simulation results of section 3.2. 


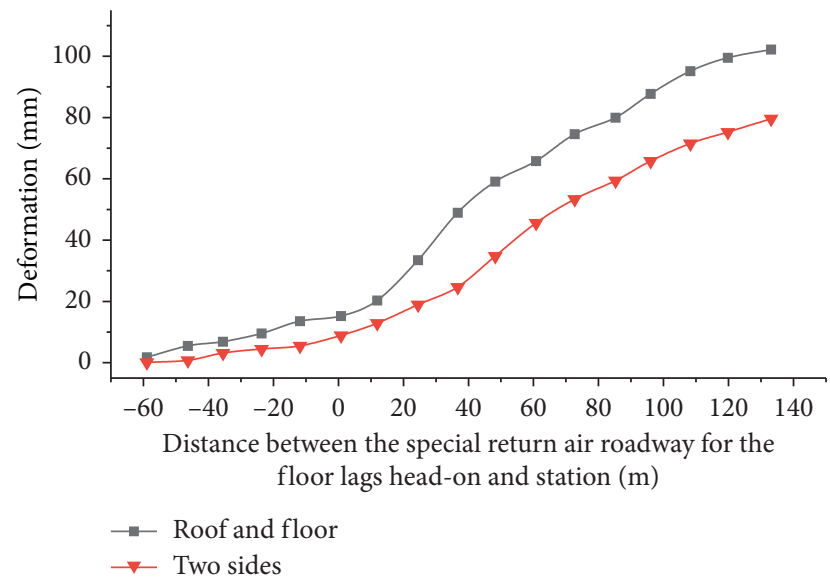

(a)

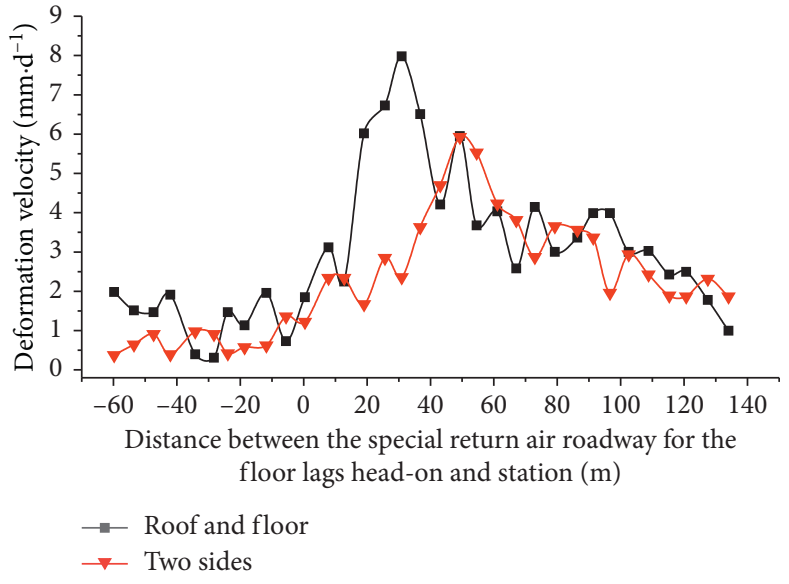

(b)

Figure 21: Deformation and deformation velocity of uphill conveyor belt roadway under the influence of special air-return roadway blast excavating: (a) deformation and (b) deformation velocity.

\section{Conclusions}

We established an FLAC3D numerical model to simulate disturbance effects under comprehensive tunneling and blasting tunneling. The results show that compared with comprehensive excavation, blasting more strongly affects the surrounding rock stress of the adjacent roadways, increases the vibration of each particle, and causes each particle to vibrate at different speeds. The front blasting side shows the highest vibration speed and the back blasting side shows the lowest vibration speed. Blasting is therefore considered to have a greater impact on the entire adjacent roadway and the factors that influence the blasting disturbance should be further studied.

The FLAC3D numerical model was established by moving the back excavation roadway horizontally and vertically by $10 \mathrm{~m}$. The results show that horizontal movement more strongly reduces the stress on the adjacent roadway compared with vertical movement. When moving vertically, the peak vibration speeds of the roof, right side, and floor plate of the first excavated roadway are clearly stronger than when moving horizontally. Increasing the horizontal distance can more effectively reduce the disturbance effect of blasting and driving between adjacent roadways compared with increasing the vertical distance.

We simulated two situations with and without bolt support after the excavation of the first roadway. The results show that the total displacement change is smaller when bolt support is applied compared with the case without bolt support. The vibration speed of each particle increases in the bolt support case. This shows that bolt support for the first excavated roadway enhances the roadway integrity, better stabilizes the rock structure surrounding the roadway, and effectively reduces surrounding rock deformation. Reasonable support for the first excavated roadway can therefore reduce the impact of blasting excavation on the adjacent roadway disturbance.

We performed industrial tests in which the approach of the roof and floor of the uphill roadway with floor return air was larger than that of the two sides. This is consistent with higher displacement of the roof and floor of the adjacent roadway monitored in the simulations compared with the two sides. There is no notable change in deformation speed of the surrounding rock when the special return air roadway of the floor passes through the uphill floor return air roadway measurement station, whereas the deformation speed curve of the uphill conveyor belt roadway changes significantly. When the blasting excavation of the deep mine roadway group is more than five times the tunnel spacing, compared with the vertical distance, the increased horizontal distance can therefore effectively reduce the disturbance effects of excavation between adjacent roadways, which verifies the simulation results of section 3.2 .

\section{Data Availability}

The data used to support the findings of this study are included within the article.

\section{Conflicts of Interest}

The authors declare no conflicts of interest.

\section{Authors' Contributions}

Jiaguang Kan and Peng Wang contributed to data curation and formal analysis. Jiaguang Kan acquired funding and reviewed and edited the manuscript. Peng Wang and Peng Wang investigated the study and provided software. Peng Wang was responsible for methodology and project administration and wrote the original draft.

\section{Acknowledgments}

The paper was financially supported by the National Natural Science Foundation of China (52074263 and 52034007) and the Fundamental Research Funds for the Central Universities (2014QNA47). 


\section{References}

[1] Z. Ding, J. Jia, X. Li, J. Li, Y. Li, and J. Liao, "Experimental study and application of medium-length hole blasting technique in coal-rock roadway," Energy Science \& Engineering, vol. 8, no. 5, pp. 1554-1566, 2020.

[2] P. Konicek, K. Soucek, L. Stas, and R. Singh, "Long-hole destress blasting for rockburst control during deep underground coal mining," International Journal of Rock Mechanics and Mining Sciences, vol. 61, pp. 141-153, 2013.

[3] X. L. Lu and Q. S. Liu, "Failure mechanism recognition and optimum support design of roadway groups in soft and fractured surrounding rock-case study: paner coal mine," Disaster Advances, vol. 6, no. S1, pp. 406-414, 2013.

[4] P. Konicek and J. Schreiber, "Heavy rockbursts due to longwall mining near protective pillars: a case study," International Journal of Mining Science and Technology, vol. 28, no. 5, pp. 799-805, 2018.

[5] J. Zuo, J. Wang, and Y. Jiang, "Macro/meso failure behavior of surrounding rock in deep roadway and its control technology," International Journal of Coal Science \& Technology, vol. 6, no. 3, pp. 301-319, 2019.

[6] L. Sun, H. Wu, B. Yang, and Q. Li, "Support failure of a highstress soft-rock roadway in deep coal mine and the equalized yielding support technology: a case study," International Journal of Coal Science \& Technology, vol. 2, no. 4, pp. 279286, 2015.

[7] H. Kang, "Support technologies for deep and complex roadways in underground coal mines: a review," International Journal of Coal Science \& Technology, vol. 1, no. 3, pp. 261-277, 2014.

[8] W. B. Lu and J. G. Wang, "Simulation of blasting vibration field in the middle and far zone of blasting Source," Blasting, vol. 13, no. 3, pp. 8-11, 1996.

[9] A. Kavetsky, G. P. F. Chitombo, C. K. McKenzie, and R. L. Yang, "A model of acoustic pulse propagation and its application to determine Q for a rock mass," International Journal of Rock Mechanics and Mining Sciences \& Geomechanics Abstracts, vol. 27, no. 1, pp. 33-41, 1990.

[10] G. G. U. Aldas and B. Ecevitoglu, "Waveform analysis in mitigation of blast-induced vibrations," Journal of Applied Geophysics", vol. 66, no. 1-2, pp. 25-30, 2008.

[11] N. H. Yang and H. liu, "Vibration field at tunnel contour induced by a close-in blasting," Engineering Blasting, vol. 6, no. 2, p. 6 10, 2000.

[12] G. Berta, "Blasting-induced vibration in tunnelling," Tunnelling and Underground Space Technology, vol. 9, no. 2, pp. 175-187, 1994.

[13] W. X. Gao and Y. T. Liu, "Damage mechanism and mechanical behaviors of rock under explosion loading," Rock and Soil Mechanics, vol. 24, no. S2, pp. 585-588, 2003.

[14] L. M. Taylor, E.-P. Chen, and J. S. Kuszmaul, "Microcrackinduced damage accumulation in brittle rock under dynamic loading," Computer Methods in Applied Mechanics and Engineering, vol. 55, no. 3, pp. 301-320, 1986.

[15] S. Satapathy, "Dynamic spherical cavity expansion in brittle ceramics," International Journal of Solids and Structures, vol. 38, no. 32-33, pp. 5833-5845, 2001.

[16] P. C. Jha and R. K. S. Chouhan, "Long range rockburst prediction: a seismological approach," International Journal of Rock Mechanics and Mining Sciences \& Geomechanics Abstracts, vol. 31, no. 1, pp. 71-77, 1994.

[17] F. H. Chehade and I. Shahrour, "Numerical analysis of the interaction between twin-tunnels: influence of the relative position and construction procedure," Tunnelling and Underground Space Technology, vol. 23, no. 2, pp. 210-214, 2008.

[18] C. W. Ng, K. M. Lee, and D. K. Tang, "Three-dimensional numerical investigations of new Austrian tunnelling method (NATM) twin tunnel interactions," Canadian Geotechnical Journal, vol. 41, no. 3, pp. 523-539, 2004.

[19] Y. F. Hu, "Stability analysis of surrounding rock of urban double-track tunnel with small interval," Chinese Journal of Rock Mechanics and Engineering, vol. 21, no. 9, pp. 1335-1338, 2002.

[20] Y. Yao, C. He, and Z. X. Xie, "Study of mechanical behavior and reinforcing measures of middle rock wall of parallel tunnel with small interval," Rock and Soil Mechanics, vol. 28, no. 9, pp. 1883-1888, 2007.

[21] J. H. Bi and J. H. Zhong, "Study on influence of blasting vibration fromexcavation of a new tunnel on existed tunnel," Engineering Blasting, vol. 10, no. 4, pp. 69-73, 2004.

[22] W. J. Yu, S. H. Du, W. J. Wang, and Y. J. Zhu, "Excavation disturbance and stability of short-distance roadway with high stress and soft rock mass," Chinese Journal of Geotechnical Engineering, vol. 36, no. 1, pp. 57-64, 2014.

[23] M. C. He, H. P. Xie, S. P. Peng, and Y. D. Jiang, "Study on rock mechanics in deep mining engineering," Chinese Journal of Rock Mechanics and Engineering, vol. 24, no. 16, pp. 28032813, 2005.

[24] Q. S. Liu, K. Shi, and X. Huang, "Analysis on site monitoring of roadway under disturbed effects by excavation of neighboring roadways," Journal of China Coal Society, vol. 36, no. 6, pp. 897-902, 2011.

[25] A. Cichowicz, A. M. Milev, and R. J. Durrheim, "Rock mass behaviour under seismic loading in a deep mine environment: implications for stope support," Journal of the Southern African Institute of Mining and Metallurgy, vol. 100, no. 2, pp. 121-128, 2000.

[26] M. Sazid and T. N. Singh, "Two-dimensional dynamic finite element simulation of rock blasting," Arabian Journal of Geosciences, vol. 6, no. 10, pp. 3703-3708, 2013.

[27] D. Saiang and E. Nordlund, "Numerical analyses of the influence of blast-induced damaged rock around shallow tunnels in brittle rock," Rock Mechanics and Rock Engineering, vol. 42, no. 3, pp. 421-448, 2009. 